\title{
ЗОНАЛЬНАЯ ЭФФЕКТИВНОСТЬ РАЗМЕЩЕНИЯ И СПЕЦИАЛИЗАЦИИ ЗЕРНОВЫХ КУЛЬТУР В ОМСКОЙ ОБЛАСТИ
}

\author{
(c) 2021 Кошелев Борис Степанович \\ доктор экономических наук, профессор кафедры менеджмента и маркетинга \\ Омский государственный аграрный университет имени П.А.Столыпина, Россия, Омск \\ E-mail: bs.koshelev@omgau.org
}

\section{(C) 2021 Асташова Екатерина Анатольевна}

кандидат экономических наук, доцент, заведующая кафедрой менеджмента и маркетинга

Омский государственный аграрный университет имени П.А.Столыпина, Россия, Омск

E-mail: ea.astashova@omgau.org

В статье рассматриваются вопросы совершенствования размещения и специализации зерновых культур по зонам Омской области. Определена зональная выгодность производства зерна, а также рассчитаны интегрированные индексы отдельных зерновых культур и индекс, показывающий какая из них более эффективна при возделывании в данной местности. Уточнены ареалы производства высококачественного зерна пшеницы и зона потенциальных возможностей (северная лесостепная зона).

Ключевые слова: Омская область, производство зерна, эффективность, размещение, специализация.

Практика реализации нового аграрного курса показала, что в значительной степени изменился подход к размещению производства продукции на конкретной территории и не всегда с достаточной эффективностью. Следует признать, в современных условиях отчасти это вынужденная мера, когда дело касается выживаемости предприятия в связи с нарушением производственно-хозяйственных связей и ценовой политикой в отношении различных видов сельскохозяйственной продукции и зерновых культур в том числе.

В общественном секторе сельского хозяйства в период его реформирования произошло интенсивное свертывание отдельных отраслей, возникли вопросы с асимметрией размещения зерновых культур и др.

Внешние и внутренние причины всегда вносят коррективы в динамику развития сельского хозяйства и определенным образом отражаются на ареалах распространения тех или иных сельскохозяйственных культур. Об этом свидетельствует весь ход развития сельского хозяйства до настоящего времени. Очевидно, и в будущем неизбежны локальные или масштабные структурные сдвиги в территориальной специализации и размещении зерновых культур как во времени, так и в пространстве, которые могут происходить под воздействием долговременно или кратковременно действующих факторов.
Каждое такое событие влечет за собой далеко идущие последствия, действие которых может сохраниться длительное время. Главным принципом здесь должно быть не администрирование и волевые решения, а понимание того, что этот процесс происходит под влиянием естественно исторического развития отрасли и определяется объективными природными, экономическими и другими факторами. Их влияние отражается на территориальном размещении зерновых культур, уровне их специализации и концентрации производства. Так, в благоприятных для зерновых культур природно-климатических условиях выше возможности ускоренного роста их производства, повышение производительности труда, снижение уровня затрат, а значит - повышения общей эффективности.

Оценка зерновых культур по этому показателю на основе урожайности и себестоимости показывает, что овес практически во всех зонах, кроме степной, не уступает по показателям эффективности ячменю, а на севере области превосходит и яровую мягкую пшеницу (табл. 1).

Таким образом, самый низкий оценочный балл в степной зоне имеет овес, а пшеница и ячмень по этим признакам близки между собой. В южной лесостепи наоборот овес имеет более высокие баллы, чем в степи. Аналогичная ситуация с ним складывается и на севере области. Только в северной зоне по результатам интегрированной 
оценки он стоит выше яровой пшеницы. Общая тенденция заключается в том, что эффективность ячменя возрастает в направлении на юг региона, а овса - на север, что накладывает свой отпечаток на динамику и размещение этих и других зерновых культур (табл. 2).

Следовательно, среди зерновых культур приоритет принадлежит яровой пшенице, которая занимает среди них монопольное положение. Вместе с тем, важность ее не всегда определялась местом и значимостью для различных территорий. Наглядным примером является размещение пшеницы по зонам области до реформирования сельского хозяйства. До 90-х годов она занимала значительные площади в северных районах при явно низкой эффективности производства и качества зерна. Так, по данным за 1986-1988 гг. хозяйства степной зоны при урожайности меньше, чем в северной лесостепи на 9,4-9,9\%, имели себестоимость зерна ниже на 22,4-39,5\%. На один человеко-час его было произведено больше, чем в хозяйствах северной части региона в 2,3 раза, а удельный вес проданного зерна в валовом сборе составил 43,2\%, против 29,3 в северной лесостепной и 13,2\% в северной зоне, однако, выручка от реализации в расчете на 1 т в хозяйствах северной зоны была выше в 1,2 раза.

Такая эффективность производства яровой пшеницы была создана искусственно использованием более повышенных цен. Они с юга на север находились в пропорции 1:1,1:1,45:1,67. Хозяйства северных районов в отдельные годы выполняли по несколько годовых планов продажи зерна государству, оставляя при этом животноводство практически без концентратов.

В последние годы ценовые приоритеты на стороне южных хозяйств региона и находятся в соотношении с юга на север: 1,0:1,0:0,90:0,70, то есть по качественным параметрам пшеница, выращиваемая для продовольственных целей, значительно уступает аналогичной из южной части области. Так как основное направление деятельности этой (северной) части области - это производство продукции животноводства, то здесь должна иметь преимущество пшеница кормового назначения. Что касается размещения посевных площадей пшеницы по зонам области, то она среди зерновых и зернобобовых культур занимает ведущее положение - об этом свидетельствует ее доля в посевах зерновых (табл. 3).

Таблица 1. Эффективность производства яровых зерновых в Омской области (балл)

\begin{tabular}{|l|c|c|c|c|}
\hline \multirow{2}{*}{ Зона } & \multicolumn{4}{|c|}{ Культура } \\
\cline { 2 - 5 } & Зерновые в среднем & Яровая пшеница & Ячмень & Овес \\
\hline Степная & 91 & 94 & 96 & 88 \\
\hline Южная лесостепная & 124 & 132 & 138 & 126 \\
\hline Северная лесостепная & 81 & 89 & 74 & 86 \\
\hline Северная & 73 & 68 & 59 & 75 \\
\hline
\end{tabular}

Таблица 2. Динамика посевных площадей зерновых культур, тыс. га

\begin{tabular}{|l|c|c|c|c|c|}
\hline \multirow{2}{*}{\multicolumn{1}{|c|}{ Культура }} & \multicolumn{5}{c|}{ Год } \\
\cline { 2 - 6 } & 1990 & 2000 & 2010 & 2015 & 2019 \\
\hline Озимая рожь & 146,3 & 27,5 & 16,3 & 10,6 & 4,7 \\
\hline Озимая пшеница & 41,1 & 07,6 & 0,5 & 2,4 & 6,7 \\
\hline Итого озимые & 187,4 & 28,1 & 16,8 & 13,0 & 11,4 \\
\hline Яровая пшеница & 1165,3 & 1307,1 & 1447,8 & 1629,2 & 1393,4 \\
\hline Ячмень & 302,1 & 255,0 & 261,4 & 314,9 & 321,5 \\
\hline Овес & 254,8 & 150,1 & 122,0 & 112,5 & 98,3 \\
\hline Просо & 15,5 & 14,2 & 3,6 & 0,9 & 3,8 \\
\hline Гречиха & 6,7 & 2,2 & 2,4 & 1,6 & 2,9 \\
\hline Зернобобовые & 105,1 & 24,0 & 18,9 & 73,7 & 86,2 \\
\hline Зерновые и зернобобовые & 2036,9 & 1780,7 & 1893,5 & 2146,0 & 1933,6 \\
\hline
\end{tabular}

Источник: разработано авторами по данным Омскстата [1, 3] 
Следует иметь ввиду, что в монополию пшеницы свою лепту внесли крестьянские (фермерские) хозяйства, которые занимают $49 \%$ всех посевов зерновых области и их них 51\% пшеницы. Если в сельскохозяйственных организациях удельный вес пшеницы по годам колеблется от 70 до $77 \%$, то в КФХ - от 78 до 80\%, а в отдельные годы и выше.

Основные площади посевов пшеницы приходятся на хозяйства степной и южной лесостепной зон. Так, если в 1990 г. они занимали в этой части области 78,5\% зерновых, то в 2019 г. - 89,1\%. Такая трансформация в структуре зерновых привела к резкому сокращению посевов пшеницы в северной лесостепной и северной зонах и к 2019 г. в сравнении с дореформенным периодом (1990 г.) в первой они уменьшились на $33,6 \%$, а во второй - в 10,9 раза. На сложившееся положение повлияли такие тенденции, как рост площадей, занятых овсом в северной зоне, а также значительное сокращение хозяйств в этой зоне.

Основная тенденция за период 20 лет состояла в том, что в степной и южной лесостепной зонах площади пшеницы возрастали до 2016 г., а затем сократились к 2019 г. на 13,4\% (1434,8 до 1243,2 тыс. га). Аналогичная ситуация сложилась и в северной части области, где уменьшение посевов пшеницы происходило более значительно. Так, с 2016 г. по 2019 г. они сократились на 31,4\% (с 218,9 до 150,2 тыс. га), а среднегодовой темп составил 7,9\%.

Из зернофуражных культур посевы ячменя поступательно возросли по годам небольшими темпами и с 2010 по 2019 гг. среднегодовой темп прироста был равен 2,2\%, а площади под овсом напротив снижались, начиная с 2010 г. (122 тыс. га), и в 2019 г. составили 98,3 тыс. га (-19,4\%).

У зональной культуры северных районов области озимой ржи, начиная с 90-х годов прошлого столетия, площади посева сокращались устойчиво по периодам и с 1990 по 2000 гг. они уменьши- лись на 65,3\%, а с 2019 г. - в 31,1 раза (с 146,3 до 4,7 тыс. га). В определенной степени это можно отнести и к озимой пшенице, которая к условиям возделывания более требовательна, чем озимая рожь и яровая пшеница. До реформирования сельского хозяйства основные ее посевы находились в Омском районе южной лесостепи, поэтому при изменении условий ресурсного обеспечения (удобрения, гербициды и др.) ее посевы резко сократились почти до нулевого уровня и только в последние годы посевы озимой пшеницы стали возрастать преимущественно в сельскохозяйственных организациях (с 1,8 в 2015 г. до 4,9 тыс. га в 2019 г.). Владельцы К(Ф)Х пока ограничены в возможностях для расширения посевов этой культуры из-за определенных сложностей технологического и ресурсного плана.

Парадоксально, но факт, посевы озимой ржи, этой традиционно северной культуры в области имели один район в степной зоне и пять (из восьми) в южной лесостепной и ни одного в северной лесостепной и северной зонах. Причинами такой ситуации являлись более низкие цены, чем на пшеницу, и риск гибели посевов.

В сибирских условиях самыми распространенными культурами для пополнения рационов животных растительным белком были горох и вика. Значение их не уменьшается и сегодня, так как снабжение животноводства шротом, жмыхами и другими белковыми добавками проблематично.

Разработки научных учреждений Сибири показывают, что расширение площади посевов зернобобовых культур и повышение урожайности за счет освоения более эффективных технологий их возделывания и новых сортов приспособленных к местным условиям позволит удовлетворить потребности животноводства в дешевом растительном белке.

В степной зоне они должны занимать $4-4,5 \%$ от площади посевов зерновых, в южной лесо-

Таблица 3. Удельный вес пшеницы в посевной площади зерновых по зонам области, \%

\begin{tabular}{|l|c|c|c|c|c|}
\hline \multirow{2}{*}{\multicolumn{1}{|c|}{ Зона }} & \multicolumn{5}{c|}{ Год } \\
\cline { 2 - 6 } & 1990 & 2000 & 2010 & 2015 & 2019 \\
\hline Степная & 71,2 & 79,3 & 81,8 & 80,2 & 74,3 \\
\hline Южная лесостепная & 57,2 & 71,8 & 75,3 & 74,3 & 70,3 \\
\hline $\begin{array}{l}\text { Северная лесостеп- } \\
\text { ная }\end{array}$ & 45,6 & 64,8 & 64,5 & 66,9 & 69,2 \\
\hline Северная & 29,7 & 46,0 & 34,7 & 21,0 & 18,8 \\
\hline По области & 55,2 & 73,5 & 76,5 & 76,0 & 72,1 \\
\hline
\end{tabular}


степи 7-7,5\% нужно отводить под горох и 1-1,5\% под вику, которую следует размещать севернее линии железной дороги (Исилькуль-Калачинск). В северной лесостепи доля зернобобовых может достигать $10 \%$, причем с ростом площадей под горох возрастает значение яровой вики. В северной зоне горох и вику рекомендуется размещать в соотношении 5-5,5 к 1-1,5\%\% зерновых.

Если в 90-м году их доля в зерновых в области была близка к рекомендуемой и составляла $5,2 \%$, то в 2019 г. - только 4,4\%. Поэтому возникает проблема поддержания сахаро-протеинового отношения в рационах животных, что ведет к перерасходу кормов и снижению эффективности животноводства. В последние годы отношение к ним постепенно меняется и их посевы возрастают. Так, за 2015-2019 гг. они увеличились на $17 \%$ или среднегодовой прирост составлял $3,4 \%$.

Особое место в зерновом балансе области занимают крупяные культуры - гречиха и просо. В отличие от других зерновых культур эти исконно сибирские культуры долгое время не пользовались вниманием специалистов сельского хозяйства. Так, просо в 2015 г. занимало только 0,9 тыс. га, что в 17 раз меньше, чем в 1990 г. и только с 2017 г. ее площади стали возрастать и в 2019 г. находились на уровне 2010 г. Посевы гречихи варьируют, начиная с 2000 г., вокруг средней их величины за этот период. Практически в области ее возделыванием занимаются только хозяйства двух районов.

Подводя итог краткого анализа сложившегося размещения и специализации зерновых культур следует отметить существующую асимметрию между отдельными зерновыми культурами, а монополия пшеницы сужает возможности производства других видов зерна, а также снабжение отраслей животноводства концентратами в южной части области. Так, в последние годы на 1 гектар продовольственного зерна приходится фуражного в степной зоне - 0,24, южной лесостепной $-0,33$, в северной лесостепной - 0,46, в северной $-3,5$ и в среднем по области $-0,30$, а в 1990 г. это соотношение было на уровне 0,48 га.

Особое место в формировании подходов к совершенствованию территориального размещения и специализации сельского хозяйства занимают вопросы размещения и концентрации посевов сельскохозяйственных культур не только в пределах природно-экономических зон, районы которых характеризуются общностью почвенно-климатических условий, но и отдель- но взятых территориальных образований на основе экономической эффективности возделывания каждой из них.

Уровень затрат на единицу продукции в данном случае будет объективным (синтетическим) показателем, характеризующим эффективность конкретной культуры в определенном периоде. К этой же категории относится и окупаемость затрат, которую можно исчислять как по группам сельскохозяйственных культур, так и по каждой из них в отдельности. Оценка сравнительной эффективности будет неполной, если не использовать для этой цели размер продукции, получаемой с единицы площади. В общем виде эти показатели дают представление об эффективности производства, но по своей сути они разнородны. Для того, чтобы получить обобщающую оценку отдачи от вложенных средств, применяется индексный метод, который позволяет измерить несоизмеримые величины какого-либо экономического явления. Единичные относят к индивидуальным, а характеризующие изменения сложного явления, состоящего из элементов, непосредственно несоизмеримых, - к сводным индексам.

Проектирование контуров экономической целесообразного размещения отдельных сельскохозяйственных культур и их групп осуществлялось на основе индексов эффективности и предпочтительности. Первый определяется по вертикали, как правило, к средним значениям области, зоны и т.д. и характеризует эффективность их размещения с позиций влияния на них различий в почвенно-климатических, технологических, организационно-экономических и других условий. Второй индекс исчисляется по горизонтали только между культурами в данном территориальном образовании и внутри однородных групп. Он показывает превосходство (предпочтительность) одних культур над другими в зависимости от того, как в одинаковых условиях конкретной зоны они используют биоклиматический потенциал данной территории. Результатом являются разные уровни продуктивности и затрат на выращивание.

Коэффициенты (индексы) предпочтительности вычисляются между культурами одной группы, например, между озимой рожью и озимой пшеницей, озимой и яровой пшеницами, яровой пшеницей и зернофуражными. Среди крупяных и зернобобовых между однородными по производственному использованию и про- 
довольственному назначению культурами. Они определяются по показателям урожайности и себестоимости, а также общей эффективности.

В современных условиях этому фактору не придается большого значения, хотя он по существу и должен быть положен в основу формирования ареалов рационального размещения зерновых культур. В условиях действия правил, диктуемых рынком, местности с неэффективным производством, которое не позволяет окупать вложенные средства, имеющие высокозатратный механизм, неизбежно будут вынуждены либо принимать меры по снижению затрат на убыточную продукцию, либо перепрофилировать производство с учетом ситуации, складывающейся на рынке.

Ввиду того, что все коэффициенты (индексы) вычисляются относительно средних данных по области, по значимости их условно можно разделить на пять групп: до 1,0 - нет эффекта; 1-1,2 - слабый эффект; 1,3-1,5 - средняя эффективность; 1,6-2,0 - высокий эффект и свыше 2,0 - очень высокая эффективность.

Такая градация позволяет оценить (приближенно), на какой стадии эффективности находится данная зерновая культура. Она служит своего рода «барометром» их состояния в зависимости от действия природных и экономических факторов (и степени их использования), а с другой стороны, является инструментом, для формирования ареалов концентрации отдельных культур в более благоприятных для них условиях.

Индексы, рассчитанные по урожайности и себестоимости зерновых в среднем и по пшенице, отражают влияние природных условий на данные показатели в условиях экстенсивного ведения зернового производства с использованием упрощенных технологий по принципу «посеял - убрал» (табл. 4).

Четкой системы с эффективностью зерновых культур по зонам области не наблюдается и северная зона по показателям урожайности и себестоимости имеет более высокие значения, чем степь и северная лесостепь. В этой зоне пшеница занимает только 24-29\% посевов зерновых, ячмень 0,6-0,8, а овес 70-75\%. Овес неприхотлив при выращивании, а при размещении по хорошим предшественникам урожаи его выше, чем пшеницы. В последние годы доля яровой пшеницы в зерновых составляла 21,0-18,8\%.

Южная лесостепная зона традиционно имеет высокие показатели эффективности зерновых, положение не меняется, если рассматривать 30нальную окупаемость затрат. Индекс этого важного признака имеет тенденцию понижаться с юга на север, что вполне закономерно, поскольку яровая пшеница имеет более высокую цену среди зерновых культур, далее следует рожь, ячмень, овес.

Гречиха имеет очень небольшие площади посева. Самую высокую эффективность она показывает в степной зоне (табл. 5).

Таким образом, анализ относительных величин эффективности по окупаемости затрат показывает, что в районах степной зоны по этому показателю приоритетными являются яровая пшеница, ячмень, просо, гречиха. Озимые неустойчивы по годам и лучшие результаты показывают в районах, тяготеющих к южной лесостепи. Здесь высокие показатели имеет озимая рожь. Стабильно высокую эффективность имеют практически все зерновые культуры в северной лесостепной зоне - озимые, яровая пшеница, овес и зернобобовые. В северной зоне данных о реализации озимой ржи нет, но это зональная культура этих районов, поэтому она в перспективе займет свою нишу, а фактически господствующее положение занял овес, который обеспечивает свыше 75\% всей выручки от зерновых.

Более полно возможности той или иной культуры в зависимости от меняющихся почвенно-климатических условий характеризует анализ технолого-экономических показателей в относительном выражении в рамках группы однородных культур. Для этой цели используются коэффициенты предпочтительности. Такой анализ, отражая значимость отдельных зерновых

Таблица 4. Индексы (коэффициенты) эффективности зерновых культур в среднем по зонам области

\begin{tabular}{|l|c|c|c|c|}
\hline \multirow{2}{*}{\multicolumn{1}{|c|}{ Зона }} & \multicolumn{4}{c|}{ Индекс } \\
\cline { 2 - 5 } & урожайности & себестоимости & эффективности & окупаемости затрат \\
\hline Степная & 0,95 & 1,00 & 0,95 & 1,20 \\
\hline Южная лесостепная & 1,17 & 1,08 & 1,23 & 1,22 \\
\hline Северная лесостепная & 0,95 & 0,98 & 0,93 & 1,07 \\
\hline Северная & 1,01 & 1,05 & 1,06 & 1,02 \\
\hline
\end{tabular}


Таблица 5. Индексы (коэффициенты) эффективности зерновых по окупаемости затрат по зонам области (2015-2019 гг.)

\begin{tabular}{|l|c|c|c|c|}
\hline \multirow{2}{*}{\multicolumn{1}{c|}{ Культура }} & \multicolumn{4}{|c|}{ Зона } \\
\cline { 2 - 5 } & степная & южная лесостепная & $\begin{array}{c}\text { северная лесостеп- } \\
\text { ная }\end{array}$ & северная \\
\hline Озимые & 0,67 & 1,38 & 1,06 & - \\
\hline Яровая пшеница & 1,21 & 1,22 & 1,12 & - \\
\hline Ячмень & 1,14 & 1,18 & 0,93 & 1,04 \\
\hline Овес & 1,01 & 1,06 & 1,06 & - \\
\hline Просо & 1,79 & 1,46 & - & - \\
\hline Гречиха & 2,36 & 1,22 & 0,48 & 1,02 \\
\hline Зерновые в среднем & 1,20 & 1,22 & 1,07 & \\
\hline
\end{tabular}

культур в связи с меняющимися зональными условиями производства, дает возможность выделить те из них, которые в рамках ограниченной территории с примерно одинаковыми почвами и климатом позволяют получать больше зерна с меньшими издержками. Индексы предпочтительности выражают превосходство одной культуры над другой, что особенно важно для районов с животноводческим уклоном. Сводные индексы предпочтительности по зерновым культурам приводятся в таблице 6.

Таким образом, преимущество озимой ржи в сравнении с пшеницей возрастает в направлении на север. При этом следует иметь в виду, что пшеница при примерно одинаковой урожайности будет выгодней озимой ржи, так как разница в цене между пшеницей 3 класса и рожью составляет 19\%. Однако следует учитывать, что во все времена озимая рожь была страховой культурой и она позволяет решать более успешно организационные проблемы сезонных работ и таким образом уменьшать потери урожая.

При установлении соотношения между яровой пшеницей. ячменем и овсом, следует учитывать общую тенденцию, которая заключается в повышении эффективности ячменя в направлении на юг, а овса на север. Однако здесь существуют внутризональные особенности. которые накладывают свой отпечаток на размещение зерновых культур, имеющих товарное значение меньше, чем пшеница. Так, районы. на территории которых расположены птицеводческие и свиноводческие комплексы, засевают ячменем площади больше других. Это же относится и к районам, хозяйства которых поставляют для них ячмень по договорам.

Сравнение ячмени с овсом показывает, что в соответствии с показателями эффективности и предпочтительности основными ареалами производства зерна ячменя являются южные районы области, а овса- северные.

Крупные культуры просо и гречиха концентрируются в южной части области, но гречиха эффективна и в северной лесостепи, а просо имеет устойчивую эффективность в степи и только в двух районах южной лесостепи.

Зернобобовые выращиваются на территории региона повсеместно, но с разной результативностью. Так, в северной лесостепи они имеют эффективную устойчивость в большинстве районов зоны. На севере эффективность зернобобовых неустойчива из-за низкой урожайности и высокой себестоимости.

Обобщение материалов по вопросам производства и реализации зерна пшеницы показали, что основными зонами выращивания высоко-

Таблица 6. Индексы предпочтительности по зерновым культурам по зонам области

\begin{tabular}{|c|c|c|c|c|c|c|}
\hline \multirow[b]{2}{*}{ Зона } & \multicolumn{2}{|c|}{ Пшеница к озимой ржи } & \multicolumn{2}{|c|}{ Пшеница к ячменю и овсу } & \multicolumn{2}{|c|}{ Ячмень к овсу } \\
\hline & озимая рожь & $\begin{array}{c}\text { яровая пше- } \\
\text { ница }\end{array}$ & ячмень & овес & ячмень & овес \\
\hline Степная & 0,65 & 1,54 & 1,16 & 0,79 & 1,45 & 0,60 \\
\hline $\begin{array}{l}\text { Южная лесостеп- } \\
\text { ная }\end{array}$ & 1,12 & 0,89 & 1,04 & 0,90 & 1,16 & 0,86 \\
\hline $\begin{array}{l}\text { Северная лесо- } \\
\text { степная }\end{array}$ & 1,37 & 0,72 & 0,86 & 0,98 & 0,87 & 1,13 \\
\hline Северная & 1,75 & 0,57 & 0,81 & 1,08 & 0,77 & 1,02 \\
\hline
\end{tabular}


качественного зерна являются районы степи и южной лесостепи. Вместе с тем имеются потенциальные районы производства такого зерна в северной лесостепной зоне при наличии новых сортов со стабильной урожайностью и клейковиной на уровне 3 класса (Большереченский, Нижнее-Омский, Саргатский , Горьковский, южная часть Муромцевского и Тюкалинского, а также северная часть Любинского района южной лесостепи).

В определенной степени может меняться значение ячменя при производстве его с пивоваренными свойствами. Это доходная культура, так как цена на него 30\% выше чем на фуражный ячмень и на $21 \%$, чем на озимую рожь, равна или выше цены на яровую мягкую пшеницу. По урожайности он не уступает или превосходит ее, меньше тратится средств на гектар посева. Поэтому в равных условиях рентабельность пивоваренного ячменя выше, чем пшеницы. Наиболее выгодна эта культура для хозяйств северной части области с хронически неустойчивой экономикой. Парадокс настоящего времени заключается в том, что пока выращивается в черноземной части области, а в перспективе может выращиваться во всех зонах, включая север, его площади должны составлять не менее 50 тыс. га.

В условиях индикативного планирования и развития многоукладности в сельском хозяйстве достаточно трудно определить конкретные площади тех или иных зерновых культур, на перспективу поскольку каждый товаропроизводитель определяет их ежегодно с учетом сложившейся ситуации на рынке и спроса на продукцию. Однако следует использовать для рационального ведения отрасли в качестве придержки структуру использования пашни для зерновых культур по зонам области, разработанную СибНИИСХ (2), представленную в табл. 7.

Наповесткудня всеболеенастойчивовыходит вопрос о совершенствовании направлений использования зерна. Многолетняя ориентация сибирского земледелия на зерно имеет в своей основе не только традиции, но и материальнотехническую базу. Производство зерна лучше всех механизировано, его легче хранить, оно удобнее в послеуборочной обработке, включая и скармливание животным. И если учесть, что его использование в этом направлении, как правило, ведется на фоне общего недостатка и низкого качества других кормов, особенно сена, силоса корнеплодов и т.д., то понятно, почему о зерне сложилось твердое мнение, как о лучшем корме. Такое перераспределение зерна в пользу применения его на фураж неизбежно ведет к уменьшению товарности, а значит и выручки, что особенно важно для степных хозяйств.

Зарубежный опыт использования зерна в качествекормавживотноводствепоказывает,что доля кормового зерна в рационе сокращается, а для решения белковой проблемы увеличиваются площади под рапсом, подсолнечником, горохом, соей [4].

Очевидно, в Омском регионе должны быть выработаны свои подходы к использованию зерновой продукции, особенно в районах, где товарное высококачественное зерно занимает в реализации значительный удельный вес и дает хозяйствам большую часть доходов. Такие разработки были выполнены в области в 70-х - 80-х годах прошлого столетия и в этот период начали осваиваться хозяйствами, но по известным причинам они не получили дальнейшего развития [2].

Таблица 7. Примерная структура использования пашни по зонам области (хозяйства всех категорий)

\begin{tabular}{|l|c|c|c|c|}
\hline \multirow{2}{*}{ Элементы структуры } & \multicolumn{4}{|c|}{ Зона } \\
\cline { 2 - 5 } & степная & $\begin{array}{c}\text { южная } \\
\text { лесостепная }\end{array}$ & $\begin{array}{c}\text { северная } \\
\text { лесостепная }\end{array}$ & северная \\
\hline Зерновые и зернобобовые & $50-58$ & $50-56$ & $48-56$ & $48-54$ \\
\hline Из них озимые & $1-3$ & $4-6$ & $6-10$ & $12-16$ \\
\hline Яровая пшеница & $40-46$ & $28-32$ & $24-30$ & $8-12$ \\
\hline Ячмень & $4-8$ & $8-12$ & $4-6$ & $4-6$ \\
\hline Овес & $1-3$ & $3-5$ & $8-14$ & $14-20$ \\
\hline Просо & $0,8-1,0$ & $0,2-0,3$ & 0,1 & - \\
\hline Гречиха & $0,2-0,3$ & $0,05-0,1$ & 0,1 & $8-14$ \\
\hline Зернобобовые & $2-4$ & $3-5$ & & $14-20$ \\
\hline
\end{tabular}


Изменения спроса населения на продукты питания, увеличение потребления животноводческой продукции в перспективе вызывает необходимость совершенствования структуры производства зерна в сторону роста в его составе зерна кормового назначения c учетом специализации зон. Фактически в 2015-2019 гг. соотношение фуражного и продовольственного зерна в валовом сборе составило: в степной зоне - 0,26; южной лесостепной - 0,38; северной лесостепной 0,46 и в северной зоне - 2,6. Следовательно, производство продовольственного зерна имеет приоритет даже в зонах животноводческой специализации, где главная задача - обеспечить поголовье животных концентратами. Поэтому следует совершенствовать размещение и специализацию отдельных зерновых культур и их концентрацию в зонах и районах, имеющих более благоприятные условия возделывания и с учетом потребностей отраслей животноводства. Эта работа не должна носить односторонний характер, нужен тщательный учет и сбалансированность зональных интересов развития зернового производства и животноводства.

На основании проведенного исследования можно сделать следующий выводы:

1. В настоящее время зерновое производство движется по экстенсивному пути преимущественно за счет использования почвенного плодородия и усиления монокультуры, что ведет к нарушению самой основы рационального земледелия, уменьшению возможностей в животноводстве по полнорационному кормлению со всеми вытекающими последствиями.

2. Ввиду того, что состояние зернового хозяйства определяет уровень производства и связанных с ним отраслей, необходим взвешенный подход к размещению зерновых культур и формирование на этой основе их рациональной специализации, обеспечивающей сбалансированное развитие всего сельскохозяйственного производства.

3. Следует выработать стратегию использования зерновой продукции в зонах товарного производства зерна высокого качества и районах животноводческой специализации. Начало решению этой проблемы в области было положено в 80-х годах прошлого столетия и эти разработки должны быть реанимированы и дополнены новым содержанием с учетом действия рыночных отношений.

\section{Библиографический список}

1. Основные показатели развития агропромышленного комплекса Омской области: Статистический сборник / Омскстат. - Ч.1. - Омск, 1991 - С. 53-56.

2. Развитие кормопроизводства в регионе: ретроспектива, тенденции, экономика: Монография /Б.С. Кошелев, Ю.А. Мирошников. - Омск: ФГБОУ ВО Омский ГАУ им. П.А. Столыпина, 2020. - С. 81-195, 258-259.

3. Растениеводство Омской области: Статистический сборник / Омскстат. - Омск, 2015-2020.

4. Совершенствование размещения и специализации сельского хозяйства Западной Сибири: Монография / Б.С. Кошелев. - Омск: изд-во ОмГАУ, 2002. - С. 79-150. 